$\xi_{p}$

\title{
Dynamic Response of High Rise Structures Under the Influence of Shear Walls
}

\author{
K. PRIYANKA ${ }^{1}$ V. SWATHI ${ }^{2}$ K.ROJA ${ }^{3}$ \\ (M.Tech) Structural Engineering, \\ Dept. of CivilEngineering, \\ Vidya Jyothi Institute of Technology \\ Assistant Professor, \\ Dept. of Civil Engineering, \\ Vidya Jyothi Institute of Technology \\ Assistant Professor, \\ Dept. of Civil Engineering, \\ Vidya Jyothi Institute of Technology.
}

\begin{abstract}
:
This examine gives the procedure to seismic generally speaking execution estimation of over the top ascent homes principally dependent on an idea of technique in the limit range. In 3D scientific configuration of thirty storied structures were produced for symmetric home Models and inspect the utilize of auxiliary assessment device ETABS. The systematic model of the building incorporates each and every single fundamental part that disturb the deformability of the shape, firmness, mass and power. To consider the impact, divider of solid center , and shear at unprecedented positions for the span of tremor, seismic assessment the utilization of direct unique, straight staticand non-straight static framework has been done. The avoidances at each and every story arrange has been looked at by utilizing seeming Equivalent static, reaction range approach notwithstanding sucker method has supplementary been done to decide potential, request and execution level of the thought about design of buildings. From the underneath research it has been resolved that non-direct weakling investigation give amazing appraisal of world and in increasing nearby inelastic twisting needs and furthermore displays plan shortcoming that could stay covered up in a versatile examination and also the execution phase of the structure. Story floats are seen in the confine as particular by code (IS: 1893-2002) indirect unique, Equivalent static and nonlinear static assessment.
\end{abstract}

Keywords:ETABS, High Rise Buildings, Shear Wall, Displacement, Story Drift.

\section{Introduction}

The arrangement of tall structures essentially incorporates a sensible diagram, vague examination, preliminary arrangement and enhancement, to safely pass on gravity and parallel weights. The essential job of an extensive variety of assistant systems used as a piece of the building sort of structures is to trade gravity stacks sufficiently. The most notable weights coming to fruition due to the effect of gravity are live load, dead load and snow stack. Other than these vertical weights, structures are moreover subjected to level weights caused by wind, shake powers. Flat weights can develop high nerves, make impact advancement or cause vibration. In this way, it is imperative for the structure to have sufficient quality against vertical loads together with acceptable strength to contradict sidelong powers. The static and dynamic essential responses of lifted structures are managed by the dispersals of transverse shear immovability and bending robustness per each story. "Taking off upgrades to the casing works inside the building or even the structure itself at some point or another after its fundamental advancement and occupation.

Fittingly created and point by point structures with shear dividers have incredible execution in seismic tremors. The shear dividers are masterminded one way, so simply sidelong powers toward that way can be confronted. Shear divider can be portrayed as helper vertical part that can contradict mixes of shear, moment and center point stack instigated by parallel breeze load and gravity stack traded to the divider from other fundamental people. The use of shear divider structure has gotten pervasiveness in tall structure advancement, especially in the improvement of organization apartment suite or office/business tower. The amazing accomplishment of structures with shear dividers in contradicting strong shudders is consolidated as "we can't remain to make strong structures planned to restrict outrageous seismic tremors without shear dividers". Shear divider restrict to the even powers. 


\subsection{Purpose of Constructing Shear Walls:}

Shear dividers are not simply planned to restrict gravity/vertical weights (on account of its self-weight and other living/moving weights), anyway they are in like manner proposed for sidelong stacks of seismic tremors/wind. The dividers are in a general sense facilitated with housetops/floors (stomachs) and other sidelong dividers running across over at right focuses, thusly giving the three dimensional soundness for the building structures. Shear divider essential structures are all the more enduring. Since, their supporting region (signify cross-sectional district of all shear dividers) with reference to mean designs zone of building, is moderately more, not in the least like by virtue of RCC encompassed structures. Dividers need to contradict the motivate powers caused by the draw of the breeze. Dividers need to restrict the shear controls that undertaking to drive the dividers over. Dividers need to contradict the parallel intensity of the breeze that endeavors to drive the dividers in and pull them a long way from the building.

\subsection{Objective of the Study}

In this examination R.C.C. building is shown, analyzed and created Layout of shear divider without any other person's information is an examination of intrigue Vs confine extent clung to the properties of shear divider sections. This can be delivered by the numerical model made in E-tabs by considering the tremor and wind powers. There is different approaches to discover the limit of an area essentially expressed as beneath

1. Protest based model

2. Romanticizing for shear structure and limit line checks

3. Glorification for flexural design(or) check

The solidness of the building is assessed by checking of Story Drifts, Lateral Displacements, Lateral Forces, Story Stiffness, Base shear, Time period, Torsion.

\subsection{Scope of the Study}

Seismic tremors are going on a great part of the time now day by day. The seismic examination and framework of structures has usually based on diminishing the threat of loss of life in the greatest expected shake. To decrease the effects caused by these seismic tremors and wind loads particular sidelong stacking systems are introduced in the structures. Position of shear dividers in unsymmetrical structures has due considerations. It is astoundingly vital to choose capable and ideal territory of shear divider.

\section{Literature Review}

\section{BozdoganK.B.,Deierlein et.al.,(2010)}

The examination discussed in inconspicuous components the showing issues, nonlinear lead and examination of the packaging shear divider essential system. An expected system which relies upon the continuum approach and one dimensional restricted part methodology to be used for parallel static and dynamic examinations of divider layout structures is presented

Shaik Kamal Mohammed Azam et. al.,(2013) the present examination on seismic execution appraisal of multistoried rc encompassed structures with shear divider. An examination of essential direct similar to quality, strength and damping properties is done. The plan of shear divider has vital impact on sidelong quality in taller structures while it has less effect on even robustness in taller structures. The plan of shear divider has significant impact on flat immovability in structures of shorter stature while it has less effect on parallel quality. The effect of shear dividers is basic to the extent the damping properties and period at the execution point for tall structures. Game plan of shear dividers symmetrically in the fringe minute contradicting edges and in a perfect world interconnected regularly inverse way surrounding the inside will have better seismic execution to the extent quality and strength.

Shahabodin1,Zaregarizi2 et al., (2013) The present examination on Comparative examination on using shear divider and concrete infill to improve seismic execution of existing structures in zones with high seismic potential. Results exhibits that strong fills have amazing quality than square in fills. while the migration affirmation of square infill's is higher than cement infill's. Workmanship infill's as sidelong contradicting segments have broad quality which can keep away from even fall in direct tremors. Execution of bond in fills is dependent on adjacent segments especially segments, so less than ideal dissatisfaction in portions due to strong center forces must be considered.

\section{Structural Modeling On Etabs}

\subsection{Problem Statement}

In the present examination, examination of $\mathrm{G}+20$ multi-story working in numerous isolates zone for wind and earth shake powers is passed on out.3D demonstrate is set up for G+20 multi-story building is in ETABS. Building has a typical size of fundamental parameters consider for the study are

$\begin{array}{ll}\begin{array}{l}\text { 1. Utility of building } \\ \text { 2. Number of stories }\end{array} & \text { Residential building } \\ \text { 3. Shape of building } & \text { Rectangular } \\ \text { 4. Type of walls } & \text { Brick wall } \\ \text { 5. Geometric details } & 3.3 \mathrm{~m} \\ \quad \text { a. Ground floor } & 3.0 \mathrm{~m} \\ \quad \text { b. Floor to floor height } & : \text { M } 30 \text { (COLUMNS AND BEAMS) } \\ \text { 6. Material details } & : \text { HYSD reinforcement of Grade Fe415 } \\ \text { a. Concrete Grade } & : 200 \mathrm{KN} / \mathrm{m}^{2} \\ \quad \text { b. All Steel Grades } & : 0.6 \mathrm{~m} \mathrm{X} 0.6 \mathrm{~m} \\ \quad \text { c. Bearing Capacity of Soil } & : 0.4 \mathrm{~m} \mathrm{X} 0.6 \mathrm{~m} \\ \text { 7. Type of Construction: R.C.C FRAMED structure } \\ \text { 8. Column } & : 0.150 \mathrm{~m} \\ \text { 9. Beams } & \\ \text { 10. Slab } & \\ \text { 11. Special considerations } & \\ \text { 2. Shear wall: Thickness } 150 \mathrm{~mm} & \end{array}$

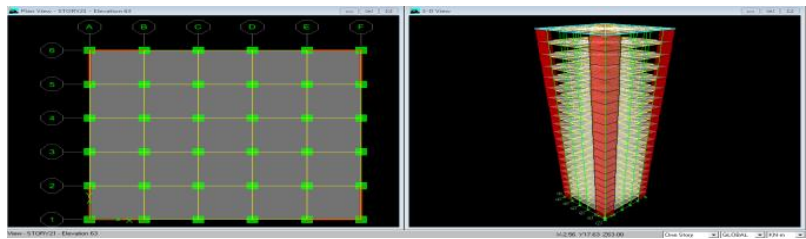

Fig:1 Shear wall at corner 

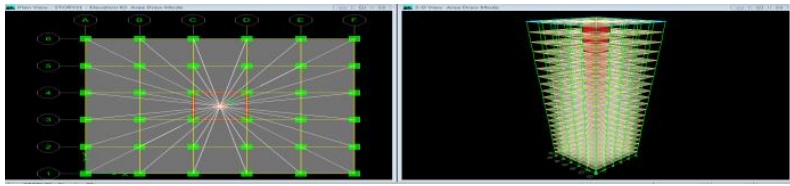

Fig:2 Shear wall at center
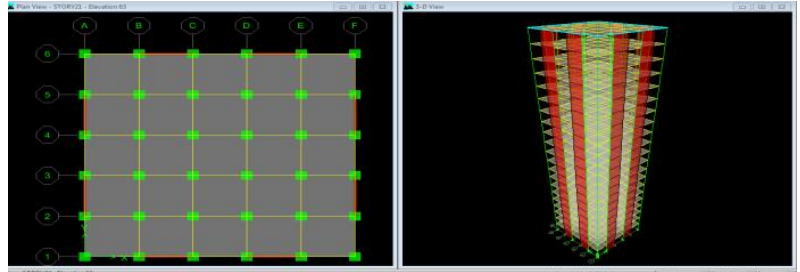

Fig:3 Shear wall at alternative positions

\section{Results And Analysis}

Table:1 Drift in X Direction

\begin{tabular}{|c|c|c|c|c|}
\hline Story & Load & $\begin{array}{c}\text { shear wall at } \\
\text { corner }\end{array}$ & $\begin{array}{c}\text { shear wall at } \\
\text { center }\end{array}$ & $\begin{array}{c}\text { Shear wall at } \\
\text { alternate position }\end{array}$ \\
\hline STORY21 & EQX & 0.001673 & 0.001448 & 0.001402 \\
\hline STORY21 & EQY & 0 & 0 & 0 \\
\hline STORY21 & WINDX & 0.000265 & 0.000254 & 0.000219 \\
\hline STORY21 & WINDY & 0 & 0 & 0 \\
\hline STORY20 & EQX & 0.001788 & 0.001585 & 0.001516 \\
\hline STORY20 & EQY & 0 & 0 & 0 \\
\hline STORY20 & WINDX & 0.000283 & 0.000278 & 0.000237 \\
\hline STORY20 & WINDY & 0 & 0 & 0 \\
\hline STORY19 & EQX & 0.001904 & 0.001725 & 0.001642 \\
\hline STORY19 & EQY & 0 & 0 & 0 \\
\hline STORY19 & WINDX & 0.000303 & 0.000305 & 0.000258 \\
\hline STORY19 & WINDY & 0 & 0 & 0 \\
\hline STORY18 & EQX & 0.00204 & 0.001884 & 0.001788 \\
\hline STORY18 & EQY & 0 & 0 & 0 \\
\hline STORY18 & WINDX & 0.000327 & 0.000336 & 0.000283 \\
\hline STORY18 & WINDY & 0 & 0 & 0 \\
\hline STORY17 & EQX & 0.002187 & 0.002053 & 0.001945 \\
\hline STORY17 & EQY & 0 & 0 & 0 \\
\hline STORY17 & WINDX & 0.000353 & 0.000369 & 0.000311 \\
\hline STORY17 & WINDY & 0 & 0 & 0 \\
\hline
\end{tabular}

\section{DRIFT X}

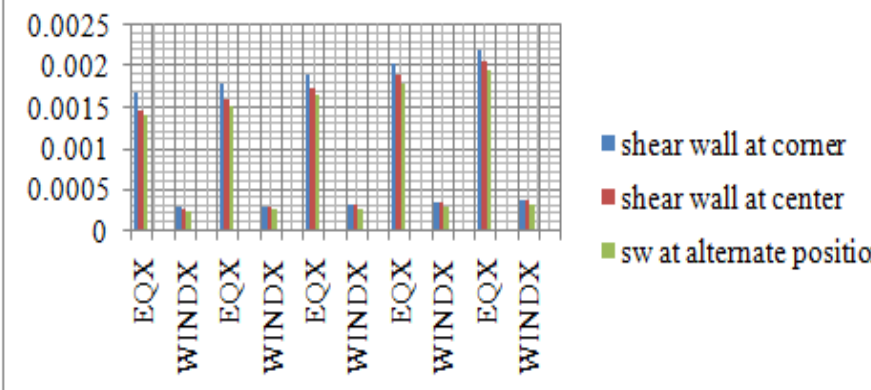

Fig:4 Shear Drift in X

Table:2 Drift in Y Direction

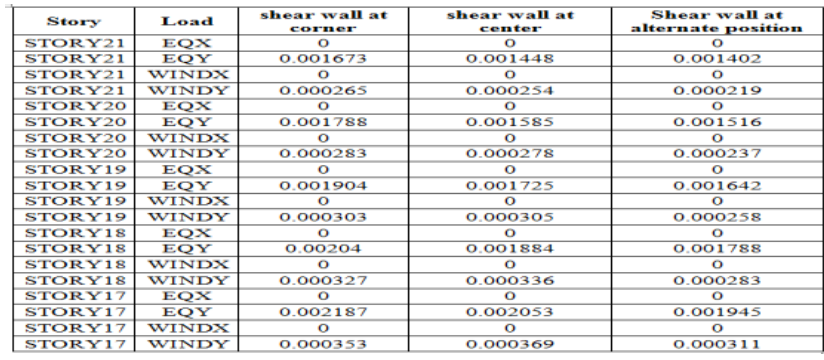

DRIFT Y

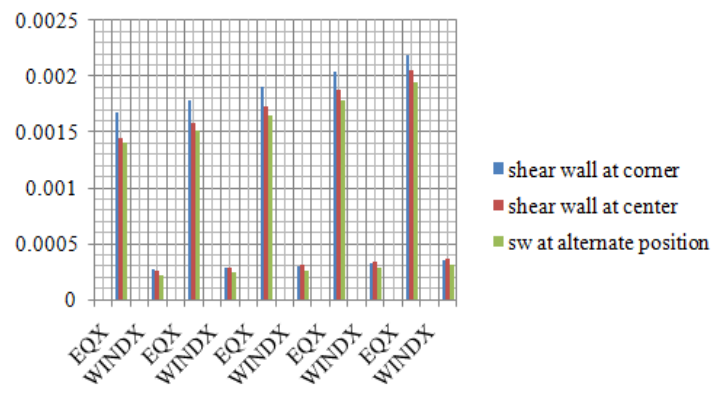

Fig:5 Shear Drift in Y

Table: 3 Story Shear (Shear Force In X Direction)

\begin{tabular}{|c|c|c|c|c|}
\hline Story & Load & $\begin{array}{c}\text { shear wall at } \\
\text { corner }\end{array}$ & $\begin{array}{c}\text { shear wall at } \\
\text { center }\end{array}$ & $\begin{array}{c}\text { sw at alternate } \\
\text { position }\end{array}$ \\
\hline STORY21 & EQX & -540.28 & -481.38 & -543.84 \\
\hline STORY21 & EQY & 0 & 0 & 0 \\
\hline STORY21 & WINDX & -46.26 & -46.26 & -46.26 \\
\hline STORY21 & WINDY & 0 & 0 & 0 \\
\hline STORY20 & EQX & -1114.2 & -990.76 & -1122.03 \\
\hline STORY20 & EQY & 0 & 0 & 0 \\
\hline STORY20 & WINDX & -138.33 & -138.33 & -138.33 \\
\hline STORY20 & WINDY & 0 & 0 & 0 \\
\hline STORY19 & EQX & -1668.36 & -1482.29 & -1680.04 \\
\hline STORY19 & EQY & 0 & 0 & 0 \\
\hline STORY19 & WINDX & -229.73 & -229.73 & -229.73 \\
\hline STORY19 & WINDY & 0 & 0 & 0 \\
\hline STORY18 & EQX & -2203.78 & -1956.88 & -2218.92 \\
\hline STORY18 & EQY & 0 & 0 & 0 \\
\hline STORY18 & WINDX & -320.48 & -320.48 & -320.48 \\
\hline STORY18 & WINDY & 0 & 0 & 0 \\
\hline STORY17 & EQX & -2721.46 & -2415.44 & -2739.68 \\
\hline STORY17 & EQY & 0 & 0 & 0 \\
\hline STORY17 & WINDX & -410.54 & -410.54 & -410.54 \\
\hline STORY17 & WINDY & 0 & 0 & 0 \\
\hline
\end{tabular}

SHEAR FORCE IN X

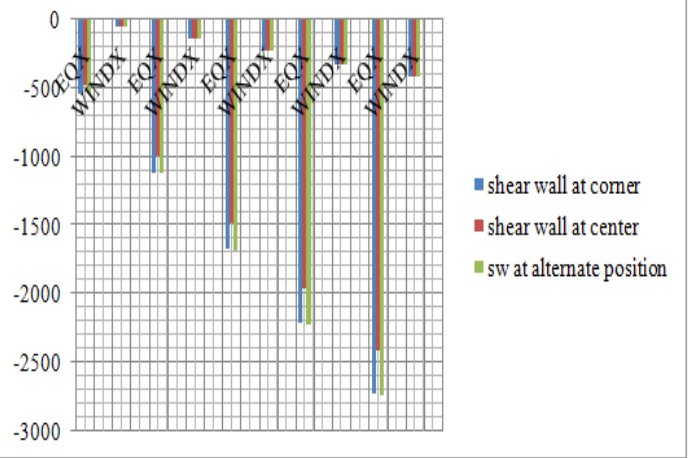

Fig:6 Shear Force in X 
Table:4 Shear Force In Y Direction

\begin{tabular}{|c|c|c|c|c|}
\hline Story & Load & $\begin{array}{c}\text { shear wall at } \\
\text { corner }\end{array}$ & $\begin{array}{c}\text { shear wall at } \\
\text { center }\end{array}$ & $\begin{array}{c}\text { Shear wall at } \\
\text { alternate } \\
\text { position }\end{array}$ \\
\hline STORY21 & EQX & 0 & 0 & 0 \\
\hline STORY21 & EQY & -540.28 & -481.38 & -543.84 \\
\hline STORY21 & WINDX & 0 & 0 & 0 \\
\hline STORY21 & WINDY & -46.26 & -46.26 & -46.26 \\
\hline STORY20 & EQX & 0 & 0 & 0 \\
\hline STORY20 & EQY & -1114.2 & -990.76 & -1122.03 \\
\hline STORY20 & WINDX & 0 & 0 & 0 \\
\hline STORY20 & WINDY & -138.33 & -138.33 & -138.33 \\
\hline STORY19 & EQX & 0 & 0 & 0 \\
\hline STORY19 & EQY & -1668.36 & -1482.29 & -1680.04 \\
\hline STORY19 & WINDX & 0 & 0 & 0 \\
\hline STORY19 & WINDY & -229.73 & -229.73 & -229.73 \\
\hline STORY18 & EQX & 0 & 0 & 0 \\
\hline STORY18 & EQY & -2203.78 & -1956.88 & -2218.92 \\
\hline STORY18 & WINDX & 0 & 0 & 0 \\
\hline STORY18 & WINDY & -320.48 & -320.48 & -320.48 \\
\hline STORY17 & EQX & 0 & 0 & 0 \\
\hline STORY17 & EQY & -2721.46 & -2415.44 & -2739.68 \\
\hline STORY17 & WINDX & 0 & 0 & 0 \\
\hline STORY17 & WINDY & -410.54 & -410.54 & -410.54 \\
\hline
\end{tabular}

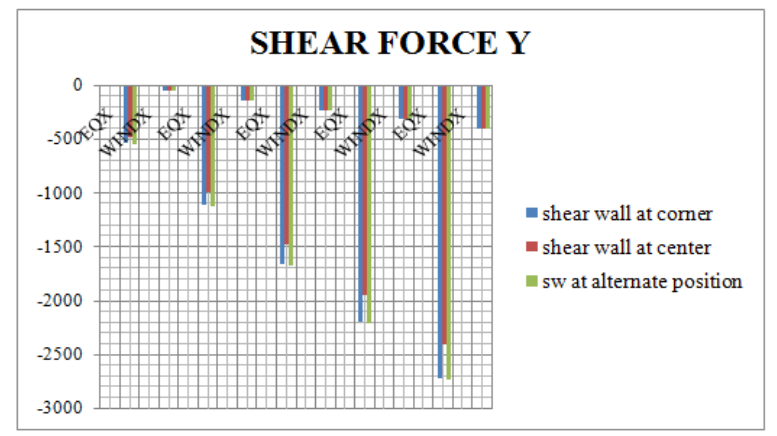

Fig:7 Shear Force in Y

Table:5 Bending Moment In X Direction

\begin{tabular}{|c|c|c|c|c|}
\hline Story & Load & $\begin{array}{c}\text { shear } \\
\text { wall at } \\
\text { corner }\end{array}$ & $\begin{array}{c}\text { shear } \\
\text { wall at } \\
\text { center }\end{array}$ & $\begin{array}{c}\text { Shear } \\
\text { wall at } \\
\text { alternate } \\
\text { position }\end{array}$ \\
\hline STORY21 & EQX & 0 & 0 & 0 \\
\hline STORY21 & EQY & 1485.83 & 1376.64 & 1496.51 \\
\hline STORY21 & WINDX & 0 & 0 & 0 \\
\hline STORY21 & WINDY & 138.77 & 138.77 & 138.77 \\
\hline STORY20 & EQX & 0 & 0 & 0 \\
\hline STORY20 & EQY & 4693.43 & 4281.43 & 4727.6 \\
\hline STORY20 & WINDX & 0 & 0 & 0 \\
\hline STORY20 & WINDY & 553.751 & 553.751 & 553.751 \\
\hline STORY19 & EQX & 0 & 0 & 0 \\
\hline STORY19 & EQY & 9563.51 & 8660.79 & 9632.73 \\
\hline STORY19 & WINDX & 0 & 0 & 0 \\
\hline STORY19 & WINDY & 1242.95 & 1242.95 & 1242.95 \\
\hline STORY18 & EQX & 0 & 0 & 0 \\
\hline STORY18 & EQY & 16039.8 & 14463.9 & 16154.5 \\
\hline STORY18 & WINDX & 0 & 0 & 0 \\
\hline STORY18 & WINDY & 2204.39 & 2204.39 & 2204.39 \\
\hline STORY17 & EQX & 0 & 0 & 0 \\
\hline STORY17 & EQY & 24069.2 & 21642.7 & 24238.5 \\
\hline STORY17 & WINDX & 0 & 0 & 0 \\
\hline STORY17 & WINDY & 3436.02 & 3436.02 & 3436.02 \\
\hline
\end{tabular}

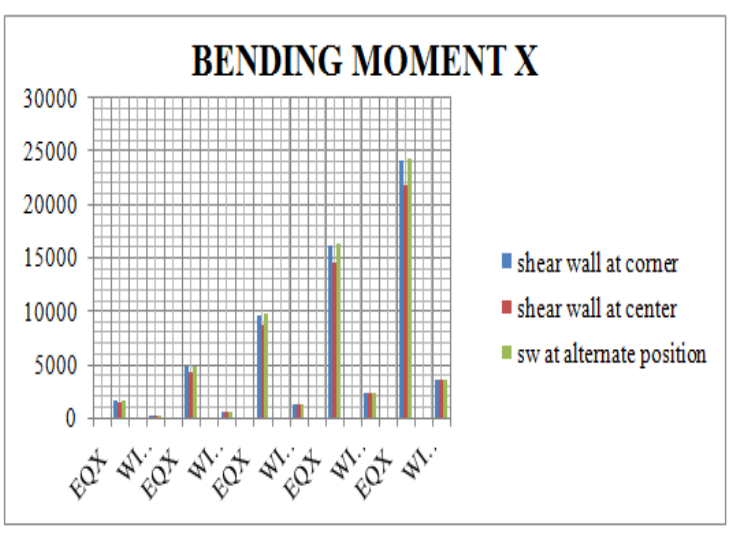

Fig:8 Bending Moment in X

Table:6 BENDING MOMENT IN Y DIRECTION

\begin{tabular}{|c|c|c|c|c|}
\hline Story & Load & $\begin{array}{c}\text { shear } \\
\text { wall at } \\
\text { corner }\end{array}$ & $\begin{array}{c}\text { shear } \\
\text { wall at } \\
\text { center }\end{array}$ & $\begin{array}{c}\text { Shear } \\
\text { wall at } \\
\text { alternate } \\
\text { position }\end{array}$ \\
\hline STORY21 & EQX & -1485.8 & -1376.6 & -1496.5 \\
\hline STORY21 & EQY & 0 & 0 & 0 \\
\hline STORY21 & WINDX & -138.77 & -138.77 & -138.77 \\
\hline STORY21 & WINDY & 0 & 0 & 0 \\
\hline STORY20 & EQX & -4693.4 & -4281.4 & -4727.6 \\
\hline STORY20 & EQY & 0 & 0 & 0 \\
\hline STORY20 & WINDX & -553.75 & -553.75 & -553.75 \\
\hline STORY20 & WINDY & 0 & 0 & 0 \\
\hline STORY19 & EQX & -9563.5 & -8660.8 & -9632.7 \\
\hline STORY19 & EQY & 0 & 0 & 0 \\
\hline STORY19 & WINDX & -1243 & -1243 & -1243 \\
\hline STORY19 & WINDY & 0 & 0 & 0 \\
\hline STORY18 & EQX & -16040 & -14464 & -16154 \\
\hline STORY18 & EQY & 0 & 0 & 0 \\
\hline STORY18 & WINDX & -2204.4 & -2204.4 & -2204.4 \\
\hline STORY18 & WINDY & 0 & 0 & 0 \\
\hline STORY17 & EQX & -24069 & -21643 & -24239 \\
\hline STORY17 & EQY & 0 & 0 & 0 \\
\hline STORY17 & WINDX & -3436 & -3436 & -3436 \\
\hline STORY17 & WINDY & 0 & 0 & 0 \\
\hline
\end{tabular}




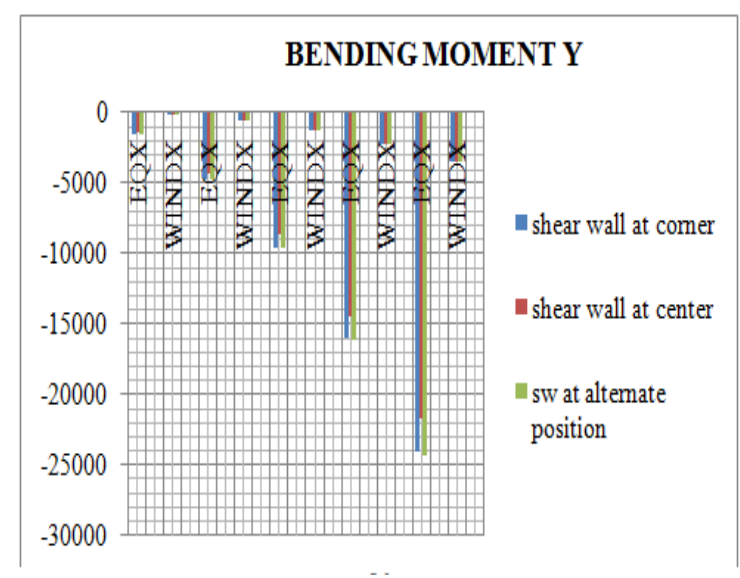

Fig:9 Bending Moment in Y
From the present examination and the outcomes got it very well may be finished up as following:

1) In is observed that, by provision of shear dividers for any structure, having less than 10 stories will impart effectively in improving the large seismic limit attributes.

2) From the correlation of story float esteems it very well may be seen that most extreme decrease in float esteems is acquired when shear dividers are given at the two corners and lift of the building.

3 ) From the story shear results it was seen that the shear divider at corner and lift is given is the best, examination of the three model composes

4) From the help responses results it was seen that the shear divider at corner and lift is given is the best, when contrasted with the other two kind of model structure

5) the ideal situation of shear dividers can be find by putting the shear dividers at better places and established that the shear divider at corner and lift is most appropriate for tall building structures.

\section{Scope for Future Research}

The volume of work attempted in this investigation is constrained to correlation of seismic reaction parameters in a working with various shear divider areas utilizing non linearanalyses. The examination could be reached out by including different parameters, for example, torsional impacts and delicate story impacts in a building. direct unique examination, push over investigation might be completed for further examination for better and practical assessment of basic reaction under seismic powers.

\section{References}

[1] HimaleeRahangdale, S.R.Satone, Design And Analysis Of Multi storied Building With Effect Of Shear Wall, Vol. 3, Issue 3, May-Jun 2013, pp.223- 232.

[2] M.Y. Kaltakci, M.H. Arslan and G.

[3] Yavuz, impact of Internal and External Shear Wall Location on Strengthening Weak RC Frames, Sharif University of Technology, August 2010, Vol.

[4] 17, No. 4, pp. 312- 323.

[5] Shaik Kamal Mohammed Azam, Vinod Hosur, Seismic Performance Evaluation of Multistoried RC framed buildings with Shear wall, International Journal of Scientific \& Engineering Research Volume 4, Issue 1, January-2013

[6] P. B. Oni, Dr. S. B.Vanakudre, Performance Based Evaluation of Shear Walled RCC Building bynon linear dynamic Analysis, International Journal of Modern Engineering Research (IJMER), Vol. 3, Issue. 4, Jul - Aug. 2013 pp-2522-2525.

[7] D. B. Karwar, Dr. R. S. Londhe, Performance of RC framed structure usingnon linear dynamic analysis, International Journal of Emerging Technology and Advanced Engineering, Volume 4, Issue 6, June 2014

[8] Yousuf Dinar, Md. Imam Hossain, Rajib Kumar Biswas, Md. Masud Rana, Descriptive study ofnon linear dynamic analysis in RC structures of Rigid joint, IOSR Journal of Mechanical and Civil Engineering (IOSR-JMCE), Volume 11, Issue 1 Ver. II (Jan. 2014), PP 60-68

[9] ATC-40.

[10] "Seismic analysis and retrofit of concrete buildings." Volume 1 and 2.

[11] Applied Technology Council, California, 1996. [5] FEMA-273.

[12] "NEHRP tips for the unstable rehabilitation of buildings." Federal Emergency Management Agency, Washington DC, 1997.

\section{[13] FEMA-356.}

[14] "Prestandard and statement for the unstable rehabilitation of buildings." Federal Emergency Management Agency, Washington DC, 2000.

Fig:10 Torsion

[15] IS: 1893 (Part 1) 2002- Indian standard- "Criteria for earthquake resistant style of structures", Bureau of Indian Standards, New Delhi.

[16] U.H. Varnayi in his second edition of "Design of structures"

\section{Conclusions}

